\section{CASE OF PUNCTURE}

OF THF.

\section{BLADDER ABOVE THE PUBES.}

BY JONATIIAY TOOGOOD, ESQ.

SFNIOR SURGFON TO THF ERIDGEWATER INFIRMARY.

Mr. C. had retention of urine from an enlarged prostate gland, which made the introduction of the catheter frequently necessary; on one occasion no water followed the introduction of the instrument, which was passed without difficulty; repeated trials were made without success; a consultation was held, and although repeated efforts were made to relieve the patient by various instruments, warm baths, and the usual means, a very inconsiderable quantity of urine only could be brought away.

Matters remained in this state for three days, when a gentleman of hospital celebrity was added to the consultation. Having formerly had the care of the patient, he apprehended no difficulty, and passed the instrument with so much ease, that he rather triumphantly desired a vessel to be brought to receive the urine, but on withdrawing the stilette, to his great surprise and mortification, no water flowed. He then determined that there was no water in the bladder, and considered the case to be one of suppression and not retention of urine, and left the patient with the full conviction that he would shortly die. But those who had watched the case from the beginning were of a different opinion, and on careful percussion of the abdomen, the bladder could be traced enormously distended. It was now determined to puncture the bladder, the retention having existed from Thursday night until the following Monday. This was done above the pubes, and a large quantity of highly offensive urine was evacuated with immediate and great relief. Very little hope, however, was entertained of the patient's recovery, for, in addition to his being upwards of seventy years old, he was very corpulent, with a pendulous belly, so that there was every reason to believe that although he might be temporarily relieved, he would sink from infiltration of urine into the surrounding parts and mortification. Shortly after the operation, an elastic catheter was introduced into the bladder through the urethra, and we had the satisfaction of seeing every drop of water pass through it. Our hopes now revived, and we became sanguine of our patient's recovery, and redoubled our efforts to save him. He was most carefully and anxiously watched, the wound was cleansed and brought together with plaster. Nothing could proceed more favourably; all the dangerous symptoms gradually subsided, the wound healed, and he again passed his water naturally, but occasionally it was drawn off. On one of these occasions a stone was distinctly felt, but although many attempts were made at different times to discover it, it could not always be detected. The wound healed firmly, and he recovered his health and spirits so as to enable him to take his usual exercise. He continued in this state for more than a year, when one afternoon he was suddenly attackcd with symptoms of peritoneal inflammation, which increased rapidly, and he died in twelve hours.

On opening the cavity of the abdomen, urine was found effused in considerable quantity from ulceration of the bladder, which appeared to have been occasioned by an angle of a calculus, nine of various sizes being found in the bladder.

The cause of failure in evacuating the contents of the bladder in this case, arose from the shortness of the instruments employed. Baron Hurteloup, to whom I related it, at once pointed it out, and said that if a catheter two feet long had been used, the operation would not have been required.

Bridgewater, Oct. 28, 1841.

\section{COMPRESSION OF THE FEMALE WAIST BY S'IAYS.}

TO THE EDITORS OF THE PROVINCIAL MEDICAL AND SURGICAL JOURNAL.

Gentremen,-On examining the body of a young female a few weeks ago, I was so much struck by the remarkable effects produced both on the bony framework of the body, and on the soft parts within, by the pressure of stays with tight lacing, that I am induced to ask you to gire insertion to a few observations on this subject.

The female in question was 23 years of age, of middle stature, and died, it was supposed, of disease in the abdomen. For different reasons, however, it is merely the phenomena which particularly attracted my attention, that I wish to allude to. In this case there was a moa satisfactory explanation given by the state of the parts, of the manner in which the female waist may be reduced to half its natural dimensions, for the lower ribs on the left side were driven upwards and inwards, so as to be folded over those of the opposite side, in such a manner, that below the xiphoid cartilage, far from there being any space between the cartilages of the lower ribs, as they mounted towards the sternum, one set was placed in front of the other.

Hence we may easily imagine what effects must have been produced on the yielding organs within. We had only time to observe the following facts :-

Thorax.-The diaphragm was driven further upwards than natural, reaching on the right side, where the liver had been pressed under it, to the level of the third rib, on the left to that of the fourth. Remembering this fact, we shall easily understand how comparatively small the space must have been for the play of the heart and lungs.

The right lung was extensively diseased. About an ounce of pale serous fluid was found in the pericardium.

The exterior circumference of the waist was about seventeen inches.

Abdomen.-The phenomenon in this cavity which most attracted my attention, was the aspect of the transverse colon, and this, we may easily suppose, cannot have been very natural, for this division of the gut, confined to a space about half the extent of that across which it is naturally stretched, was of necessity folded on itself, in such manner as must have impeded, in no inconsiderable degree, the passage of the fæces along its canal, thus giving rise to constipation of the 